\title{
Epidemiology of Surgical Treatment of Adolescent Sports Injuries in the United States: Analysis of the MarketScan Commercial Claims and Encounters Database
}

\author{
Nicholas Bonazza, M.D., Dallas M. Smuin, M.D., Nicholas Sterling, M.D., Ph.D., \\ Djibril Ba, M.P.H., Guodong Liu, Ph.D., Douglas L. Leslie, Ph.D., William Hennrikus, M.D., \\ and Aman Dhawan, M.D.
}

\begin{abstract}
Purpose: To determine whether there is increasing surgical management of adolescent sports injuries and whether the average age of surgical patients is decreasing. Methods: The Truven Health MarketScan Database was searched from 2008 to 2014 for patients 10 to 19 years of age using the International Classification of Disease, 9th Revision codes and Current Procedure Terminology, 4th Edition, codes for operative treatment for the following conditions: anterior cruciate ligament (ACL) injuries, knee collateral ligament (KCL) injuries, meniscal injuries, Osgood-Schlatter syndrome, and elbow ulnar collateral ligament injuries. Patients identified were characterized by sex, age, year of injury, and type of residence (urban vs rural) based on metropolitan statistical areas. Results: A total of 516,892 patients sustained 1 of the identified injuries, and 133,541 $(25.8 \%)$ patients underwent a related surgery. KCL and meniscal injuries demonstrated a consistent increase in the rate of surgical intervention $(P<.0001)$. Average age of surgical intervention did not increase or decrease overall for any diagnosis. Female adolescents were more likely to undergo surgery for KCL injuries (adjusted odds ratio [aOR] 1.7, 95\% confidence interval [CI] 1.58-1.79, $P<.0001$ ), Osgood-Schlatter syndrome (aOR 1.8, 95\% CI 1.38-2.39, $P<.0001$ ), and ACL injuries (aOR 1.5, 95\% CI 1.45-1.52, $P<.0001$ ), whereas male adolescents were more likely to undergo surgery for meniscal injuries (aOR 1.3, 95\% CI 1.24-1.30, $P<.0001$ ) and ulnar collateral ligament injuries (aOR 1.1, 95\% CI 1.06-1.23, $P<.0005$ ). Patients in rural areas were more likely to undergo surgical intervention for ACL and meniscal injuries $(P<.0001)$ and KCL injuries $(P=.02)$. Conclusions: We found that surgical treatment of 5 common sports injuries remains stable, with only KCL injuries and meniscal injuries showing an increase in surgical incidence. Average age of surgical intervention did not change significantly over the 7-year time span for any diagnosis. Level of Evidence: Level IV, Cross Sectional Study.
\end{abstract}

C oncerns remain about increased incidence of injuries in youth athletes and sequelae of such injuries, including surgery. ${ }^{1-8}$ Variability in study

From the Penn State Hershey Bone $\theta$ Joint Institute, Hershey, Pennsylvania, U.S.A.

The authors report the following potential conflicts of interest or sources of funding: A.D. received an Orthopaedic Research Initiation grant from Penn State University, grant funding from the U.S. Department of Defense, and a grant from Revotek; is a consultant for Smith $\theta$ Nephew; and received payment for lectures, including speaker's bureaus, from Smith $\theta$ Nephew and BioMet. Full ICMJE author disclosure forms are available for this article online, as supplementary material.

Received July 11, 2019; accepted July 12, 2019.

Address correspondence to Aman Dhawan, M.D., Penn State Hershey Bone $\theta$ Joint Institute, 30 Hope Dr., Building B, Suite 2400, Hershey, PA 17033, U.S.A.E-mail: sportsandshoulderdoc@gmail.com

(C) 2019 by the Arthroscopy Association of North America. Published by Elsevier Inc. This is an open access article under the CC BY-NC-ND license (http://creativecommons.org/licenses/by-nc-nd/4.0/).

2666-061X/19870

https://doi.org/10.1016/j.asmr.2019.07.004 populations as well as injuries has resulted in inconsistent findings. ${ }^{5,6,9-17}$ Bayt and Bell $^{6}$ identified an overall increase in sport-related injuries presenting to an emergency department in patients age 5 to 18 years from 2001 to 2013, although they noted that injury trends varied by sport. Lykissas et al., ${ }^{5}$ however, found that the incidence of sports-related injuries actually decreased from 2000 to 2010 among patients age 5 to 14 years within the same database. Werner et al. ${ }^{15}$ looked specifically at anterior cruciate ligament (ACL) injuries and reconstruction within the Pearl Diver database and found increases in the overall number of both diagnoses and surgeries in patients age 5 to 19 years from 2007 to 2011 .

Several studies have looked at trends in surgical management of sports injuries in the pediatric and adolescent population. ${ }^{11,14,15,18,19}$ These studies have used state-specific or institution-specific series of 
Table 1. International Classification of Diseases, Ninth Revision (ICD-9) Codes Queried for the Researched Conditions

\begin{tabular}{|c|c|}
\hline Condition & ICD-9 Codes \\
\hline $\begin{array}{l}\text { Anterior cruciate } \\
\text { ligament injuries }\end{array}$ & $\begin{array}{l}\text { 717.83 - Old disruption of anterior } \\
\text { cruciate ligament } \\
717.84 \text { - Old disruptions of posterior } \\
\text { cruciate ligament } \\
844.2 \text { - Sprain of cruciate ligament of } \\
\text { knee }\end{array}$ \\
\hline Meniscal injuries & $\begin{array}{l}\text { 717.0 - Old bucket handle tear of medial } \\
\text { meniscus } \\
\text { 717.1 - Derangement of anterior horn } \\
\text { of medial meniscus } \\
\text { 717.2 - Derangement of posterior } \\
\text { horn of medial meniscus } \\
\text { 717.3 - Other and unspecified } \\
\text { derangement of medial meniscus } \\
\text { 717.40 - Derangement of lateral } \\
\text { meniscus unspecified } \\
\text { 717.41 - Bucket handle tear of lateral } \\
\text { meniscus } \\
717.42 \text { - Derangement of anterior } \\
\text { horn of lateral meniscus } \\
717.43 \text { - Derangement of posterior } \\
\text { horn of lateral meniscus } \\
\text { 717.49 - Other derangement of } \\
\text { lateral meniscus } \\
717.5 \text { - Derangement of meniscus not } \\
\text { elsewhere classified } \\
836.0 \text { - Tear of medial cartilage or } \\
\text { meniscus of knee current } \\
836.1 \text { - Tear of lateral cartilage or } \\
\text { meniscus of knee current } \\
836.2 \text { - Other tear of cartilage or } \\
\text { meniscus of knee current }\end{array}$ \\
\hline $\begin{array}{l}\text { Knee collateral } \\
\text { ligament injuries }\end{array}$ & $\begin{array}{l}717.81 \text { - Old disruption of lateral } \\
\text { collateral ligament } \\
717.82 \text { - Old disruption of medial } \\
\text { collateral ligament } \\
844.0 \text { - Sprain of lateral collateral } \\
\text { ligament of knee } \\
844.1 \text { - Sprain of medial collateral } \\
\text { ligament of knee }\end{array}$ \\
\hline $\begin{array}{l}\text { Osgood-Schlatter } \\
\text { syndrome }\end{array}$ & $\begin{array}{l}732.4 \text { - Juvenile osteochondrosis of } \\
\text { lower extremity excluding foot }\end{array}$ \\
\hline $\begin{array}{l}\text { Ulnar collateral } \\
\text { ligament (elbow) }\end{array}$ & $\begin{array}{l}\text { 841.1 - Ulnar collateral ligament sprain } \\
\text { 841.3 -Ulnohumeral (joint) sprain }\end{array}$ \\
\hline
\end{tabular}

patients that may not accurately depict trends in surgical management nationally secondary to smaller numbers of patients as well as a lack of geographic diversity within the patient population.

The purpose of our study was to use a large national database to characterize the incidence of surgical procedures for 5 adolescent sports orthopaedic injuries-ACL injuries, knee collateral ligament (KCL) injuries, meniscal injuries, Osgood-Schlatter syndrome, and ulnar collateral ligament (UCL) of the elbow injuries-based on age, sex, and year of injury. Our hypothesis was that surgical management for each diagnosis would demonstrate increasing incidence and that the average age of patients undergoing surgery would be decreasing over the study period for each diagnosis.

\section{Methods}

A search of the Truven Health MarketScan Database was conducted to identify the incidence of surgical treatment for various pediatric orthopaedic conditions from 2008 through 2014. The MarketScan Commercial Claims and Encounters Database is a medical and drug insurance claims database that contains inpatient and outpatient records and services from non-public insurers across all 50 states. It consists of data from more than 100 insurance companies and large employers and contains data on an average of more than 50 million patients per year over the study period within the United States. The database was searched for patients who had International Classification of Disease, 9th Revision (ICD-9) codes for the following conditions: ACL injuries, KCL injuries, meniscal injuries, Osgood-Schlatter syndrome, and elbow UCL injury. Only patients aged 10 to 19 years were included, consistent with the World Health Organization definition of an adolescent individual. A full list of codes is found in Table 1.

Patients were further characterized by the presence or absence of surgical treatment as designated by Current Procedural Terminology, 4th Edition codes for the aforementioned conditions. A full list of codes is found in Table 2.

Patients identified were characterized by sex, age, year of injury, and type of residence (urban vs rural) based on metropolitan statistical areas. Surgical incidence was calculated by dividing the number of adolescents undergoing surgery for a related ICD-9 code by the total number of new patients with that ICD-9 code each year as well as over the study period. Any individual sustaining an injury was removed from further years of the study to eliminate duplicate entries. Although this may represent an additional injury, due to the nature of ICD-9 coding, this far more likely represents the previous injury sustained and follow up. Multivariable regression analysis was used to evaluate differences in surgical trends between individual patient groups delineated by age, sex, and type of residence. The Cochran-Armitage trend test was used to identify significant differences in surgical trends. A waiver was granted by the institutional review board after review of the study methodology.

\section{Results}

A total of 516,892 patients sustained one of the identified injuries, and a total of 133,541 (25.8\%) patients underwent a related surgery during the study period. Surgery was performed for $64,358(54.7 \%)$ of 117,753 patients (total identified codes $1,341,091$ ) with an ACL injury, 3839 (3.7\%) of 105,210 patients 
Table 2. Current Procedural Terminology, 4th Edition (CPT-4) Codes for Surgical Procedures Associated With Queried Researched Conditions

\begin{tabular}{|c|c|}
\hline Condition & CPT-4 Codes \\
\hline Anterior cruciate ligament injuries & $\begin{array}{l}27407 \text { - Repair, primary, torn ligament and/or capsule, knee; cruciate } \\
27409 \text { - Repair, primary, torn ligament and/or capsule, knee; collateral and cruciate } \\
\text { ligaments } \\
27427 \text { - Ligamentous reconstruction (augmentation), knee; extra-articular } \\
27428 \text { - Ligamentous reconstruction (augmentation), knee; intra-articular (open) } \\
27429 \text { - Ligamentous reconstruction (augmentation), knee; intra- (open) and extra-articular } \\
29888 \text { - Arthroscopically aided anterior cruciate ligament repair/augmentation or } \\
\text { reconstruction } \\
29889 \text { - Arthroscopically aided posterior cruciate ligament repair/augmentation or } \\
\text { reconstruction }\end{array}$ \\
\hline Knee collateral ligament injuries & $\begin{array}{l}27409 \text { - Repair, primary, torn ligament and/or capsule, knee; collateral and cruciate ligaments } \\
27427 \text { - Ligamentous reconstruction (augmentation), knee; extra-articular } \\
27428 \text { - Ligamentous reconstruction (augmentation), knee; intra-articular (open) } \\
27429 \text { - Ligamentous reconstruction (augmentation), knee; intra- (open) and extra-articular }\end{array}$ \\
\hline Meniscal injuries & $\begin{array}{l}27403 \text { - Arthrotomy with meniscus repair, knee } \\
29868 \text { - Arthroscopy, knee, surgical; meniscal transplantation (includes arthrotomy for } \\
\text { meniscal insertion), medial or lateral } \\
29880 \text { - Arthroscopy, knee, surgical; with meniscectomy (medial AND lateral, including any } \\
\text { meniscal shaving) including debridement/shaving of articular cartilage (chondroplasty), same } \\
\text { or separate compartment(s), when performed } \\
29881 \text { - Arthroscopy, knee, surgical; with meniscectomy (medial OR lateral, including any } \\
\text { meniscal shaving) including debridement/shaving of articular cartilage (chondroplasty), same } \\
\text { or separate compartment(s), when performed } \\
29882 \text { - Arthroscopy, knee, surgical; with meniscus repair (medial OR lateral) } \\
29883 \text { - Arthroscopy, knee, surgical; with meniscus repair (medial AND lateral) } \\
\text { G0428 - Collagen Meniscus Implant procedure for filling meniscal defects (e.g., CMI, } \\
\text { collagen scaffold, Menaflex) }\end{array}$ \\
\hline Osgood-Schlatter syndrome & 27360 - Excision procedures on the femur (thigh region) and knee joint \\
\hline Ulnar collateral ligament of the elbow & $\begin{array}{l}24343 \text { - Repair lateral collateral ligament, elbow, with local tissue } \\
24344 \text { - Reconstruction lateral collateral ligament, elbow, with tendon graft (includes } \\
\text { harvesting of graft) } \\
24345 \text { - Repair medial collateral ligament, elbow, with local tissue } \\
24346 \text { - Reconstruction medial collateral ligament, elbow, with tendon graft (includes } \\
\text { harvesting of graft) } \\
29830 \text { - Arthroscopy, elbow, diagnostic, with or without synovial biopsy (separate } \\
\text { procedure) } \\
29834 \text { - Arthroscopy, elbow, surgical; with removal of loose body or foreign body } \\
29835 \text { - Arthroscopy, elbow, surgical; synovectomy, partial } \\
29836 \text { - Arthroscopy, elbow, surgical; synovectomy, complete } \\
29837 \text { - Arthroscopy, elbow, surgical; debridement, limited } \\
29838 \text { - Arthroscopy, elbow, surgical; debridement, extensive }\end{array}$ \\
\hline
\end{tabular}

(total identified codes 316,367 ) with a KCL injury, $60,034(38.5 \%)$ of 155,845 patients (total identified codes 618,316$)$ with a meniscal injury, $211(0.2 \%)$ of 115,635 patients (total identified codes 212,468 ) with Osgood-Schlatter syndrome, and $5099(22.7 \%)$ of 22,449 patients (total identified codes 86,447 ) with a UCL injury (Table 3 ).

For ACL injuries, the rate of surgical intervention was lowest in 2008 at $43.4 \%$ and increased to $57.2 \%$ in $2009(P<.001)$. This change was statistically significant; however, this was not a sustained trend, as there was a statistically significant decrease from 2009 $(57.2 \%)$ to $2010(53.4 \%)(P<.001)$. Year-to-year increases were observed thereafter, with one increasing to statistical significance. The rate fluctuated between the low of $43.4 \%$ in 2008 and the high of $58.6 \%$ in 2014 (Fig 1).
Analysis of KCL surgery/injuries ratio demonstrated an increase in the rate of surgical intervention every year during the study period from $2.0 \%$ in 2008 to $5.3 \%$ in $2014(P<.001)$, the exception being the final year, which did show an increase but was not statistically significant (Fig 1). The rate of surgical intervention for meniscal injuries increased from $33.2 \%$ in 2008 to $41.5 \%$ in $2014(P<.001)$ with 2 years revealing a statistically significant raise in percent surgical intervention (Fig 1).

Surgery for UCL injuries ranged from $22.1 \%$ in the final year of the study to $24.6 \%$ in 2009 . The year-to-year fluctuations were not statistically significant. Ultimately, there was no statistically significant increase in the ratio over the study period (Fig 1). The rate of surgery for Osgood-Schlatter remained low throughout the study, ranging from $0.12 \%$ to $0.21 \%$. No statistically significant 


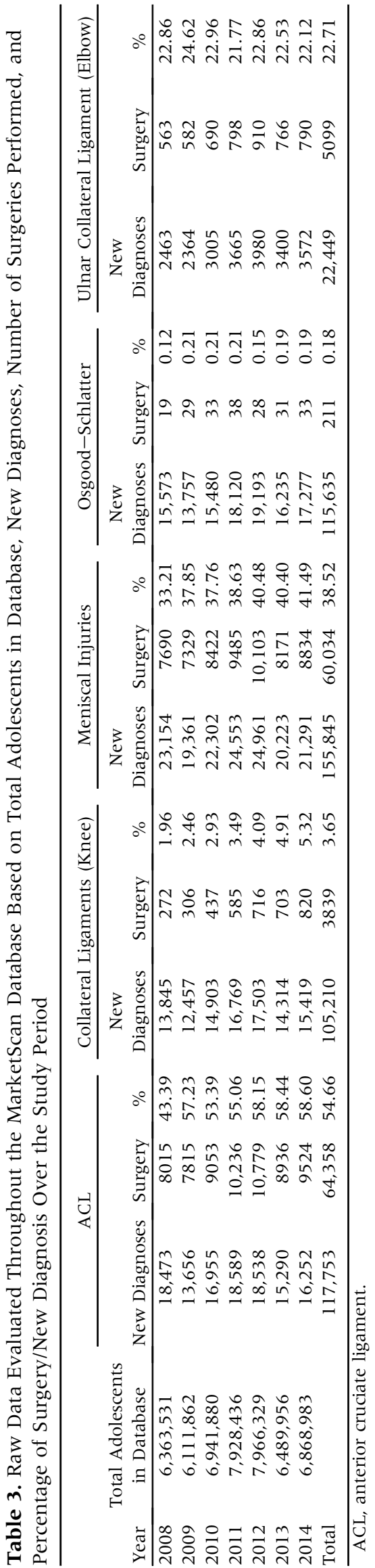

changes were noted for Osgood-Schlatter surgical to diagnosis ratio (Fig 1).

The average age of surgical intervention over 7 years was 16.35 years for ACL injuries (range 16.2816.42 years), 16.42 years for KCL injuries (range 16.26-16.59 years), 16.35 for meniscal injuries (range 16.30-16.39 years), 16.82 years for UCL injuries (range 16.66-16.97 years), and 15.9 years for Osgood-Schlatter syndrome (range 15.5-16.3 years) (Fig 2). No consistent decrease or increase in average age of surgical intervention during the study period was observed. Age greater than 15 years was associated with a greater likelihood for surgical intervention for all diagnoses $(P<.001)$ (Table 4$)$.

Female adolescents were more likely to undergo surgery for ACL injuries (adjusted odds ratio [aOR] $1.5,95 \%$ confidence interval [CI] 1.45-1.52, $P<$ $.0001)$, KCL injury (aOR 1.7, 95\% CI 1.58-1.79, $P<.0001)$, and Osgood-Schlatter syndrome (aOR1.8, 95\% CI 1.38-2.39, $P<.0001$ ) whereas male adolescents were more likely to undergo surgery for meniscal injuries (aOR 1.3, 95\% CI 1.24-1.30, $P<$ .0001 ) and UCL injuries (aOR1.1, 95\% CI 1.06-1.23, $P=.0005)$. Both male and female patients demonstrated a sustained increase in surgery for KCL injuries and meniscal injuries over the study period. All other evaluated diagnoses failed to demonstrate a trend specific to either sex (Fig 2).

Patients in rural areas were more likely to undergo surgical intervention for ACL (aOR 1.1, 95\% CI 1.03$1.10, P<.0001$ ) and meniscal injuries (aOR 1.1, 95\% CI 1.08-1.14, $P<.0001$ ) and KCL injuries (aOR 1.1, $95 \%$ CI 1.02-1.20, $P=.02$ ) whereas other diagnoses showed no statistically significant difference (Table 4).

\section{Discussion}

Although our data found a consistent increase in the incidence of surgical intervention for patients sustaining a KCL injury or meniscal injury, contrary to our hypothesis, other diagnoses including ACL tears and UCL injury failed to show a sustained increase in the incidence of surgical intervention over the 7-year study period. In addition, average age of surgical intervention did not consistently increase or decrease for any of the studied diagnoses.

The aforementioned findings contradict the findings of other studies that have looked at trends in surgical intervention for sports injuries in youth and adolescent populations. ${ }^{10,11,14,15,18}$ Dodwell et al. ${ }^{11}$ used the New York Statewide Planning and Research Cooperative System (SPARCS) database and identified an almost 3 -fold increase in the incidence in ACL reconstruction among 25,315 patients from 3 to 20 years of age from 1990 to 2009. Werner et al. ${ }^{15}$ used the Pearl Diver database and also found that overall numbers of ACL injury diagnoses and reconstructions increased from 


\section{Average Age of Patients Undergoing Surgery By Diagnosis and Year}

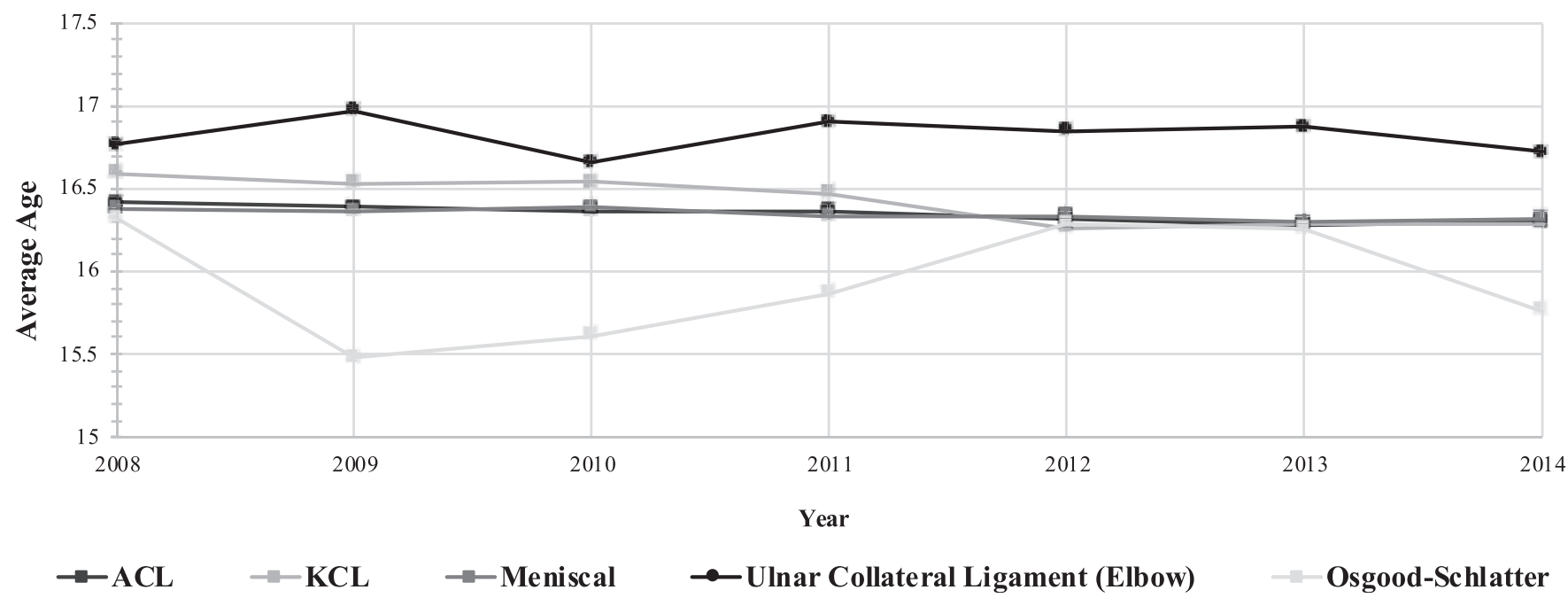

Fig 1. Rate of surgical intervention for injured patients by year. ${ }^{*} P$ value $<.05$. ${ }^{*} P$ value $<.001$. Results of the analysis are that anterior cruciate ligament (ACL), knee collateral ligament (KCL), and meniscal surgeries had an increased incidence as shown. (UCL, ulnar collateral ligament.)

2007 to 2011, although incidence data were not available. Although our study showed a $30 \%$ increase in ACL reconstructions from 2008 to 2009 (43.4\%$57.2 \%)$, this trend did not continue through the study period, as can be seen in Figure 1. The results of our data may indicate a change in the approach to adolescent ACL injuries over a more recent study period and also may be reflective of a the smaller time period in our study ( 1 decade vs 2 in the study of Dodwell et al. $\left.{ }^{11}\right)$. On the contrary, this may be a more accurate representation of the national trend in ACL injury management, given the significantly higher number of patients from across the country seen in the current MarketScan database.

Hodgins et al. ${ }^{18}$ also looked at the SPARCS database from 2002 to 2011 . They identified a 193\% increase in the total number of UCL injuries and a 3-fold increase in the rate of UCL reconstructions, noting a significant increase specifically among patients 17 to 18 and 19 to 20 years of age. Petty et al. ${ }^{10}$ noted an increase in the proportion of 694 UCL reconstructions performed at their institution that were for high school athletes ( $8 \%$ vs $13 \%$ ) from 1988 to 2003 . Differences between our study findings and the previously mentioned studies may be attributed to a potential shift in the approach to UCL injuries or a more accurate reflection of the national trend in UCL management as our study evaluated a significantly greater number of patients from across the country seen in the current MarketScan database. Previous studies also looked at a shorter time frame, and the differences observed in these studies may represent a local short trend (year to year, as was seen in our database for ACL reconstructions from 2008 to 2009) versus a true trend over time. Our study found that incidence of UCL surgery ranged from a low of $21.8 \%$ in 2011 to a high of $24.6 \%$ in 2009 with no consistent change over the study period.

Our sex-specific trends also showed varying agreement with previous findings. Hodgins et al. ${ }^{18}$ noted that male adolescents were 11.8 times more likely to undergo UCL reconstruction than female adolescents in their study, whereas our data demonstrated surgery was more likely in males with an odds ratio of 1.14 $(P<.0005)$. In another study, Dodwell et al. ${ }^{11}$ found that male adolescents were $15 \%$ more likely to undergo ACL reconstruction as opposed to female adolescents, similar to our data. The much larger number of patients and the geographic diversity of our database, as well as the more recent time period, may represent a more accurate and recent representation of the national trend to operate on these injuries.

The clinical response to our findings is intriguing. We believe these data and evaluation may help young patients understand that surgery is not the answer to every injury. The influence of professional athletics and social media may affect the patients desire to dictate their own care. We believe that treatment should be a joint decision between provider and patient, but that it should be driven by the odds for most favorable outcome. Although some injuries are best treated surgically, it is the job of the surgeon to help guide and direct the patient and their family towards the best individualized treatment. Our study helps affirm to patients, and the surgeon, of the national 
ACL Surgical Ratio
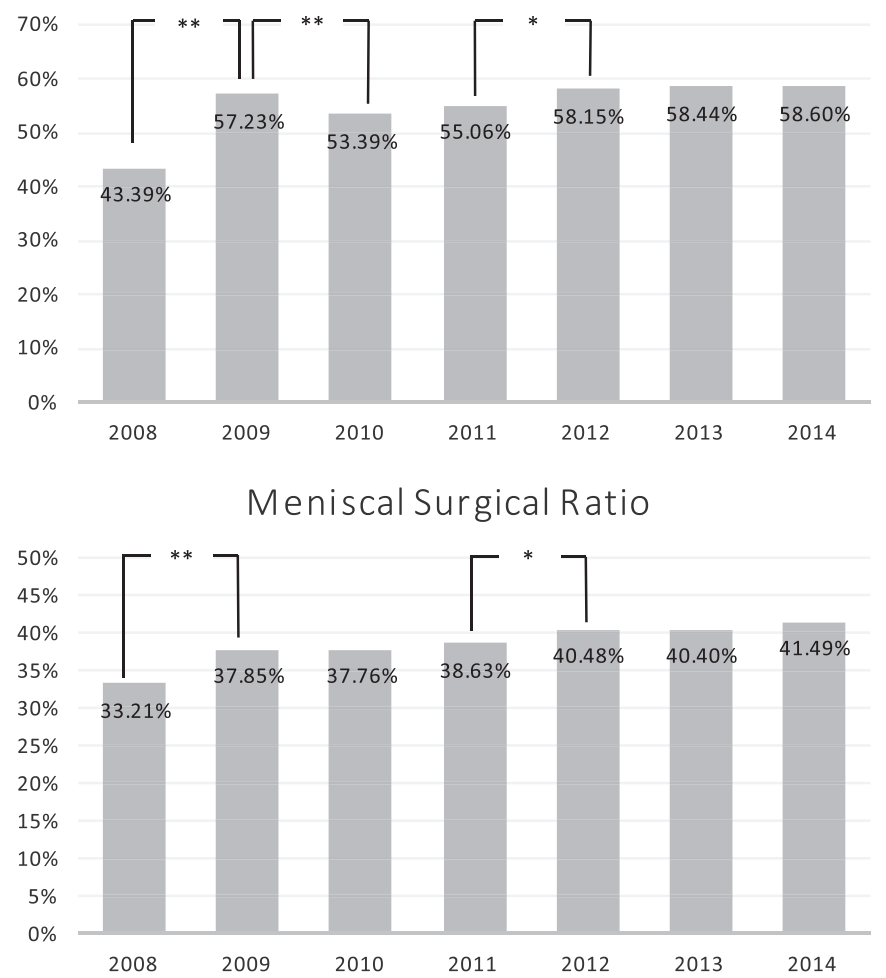

KCL Surgical Ratio

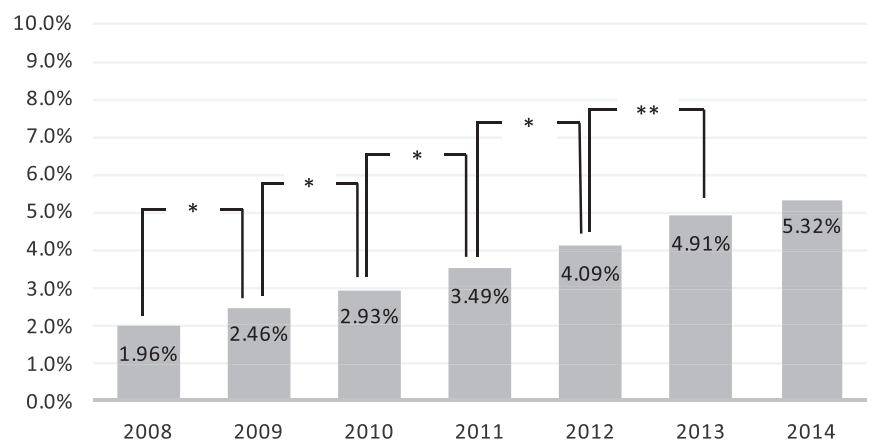

UCL Surgical Ratio

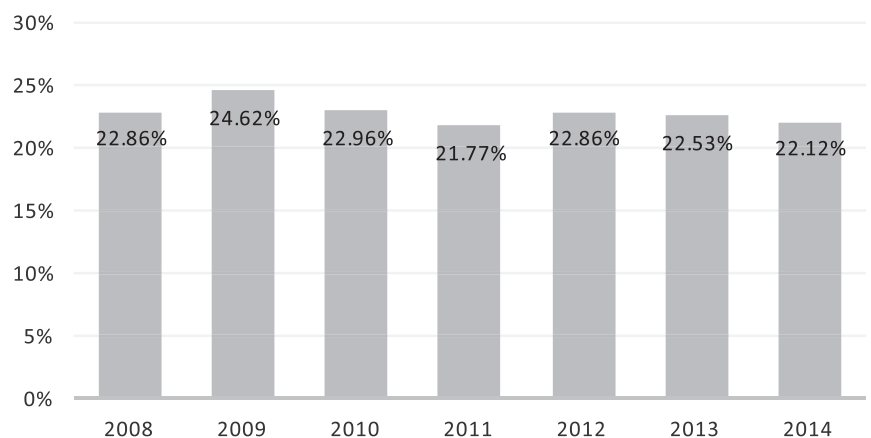

Osgood-Schlatter Surgical Ratio

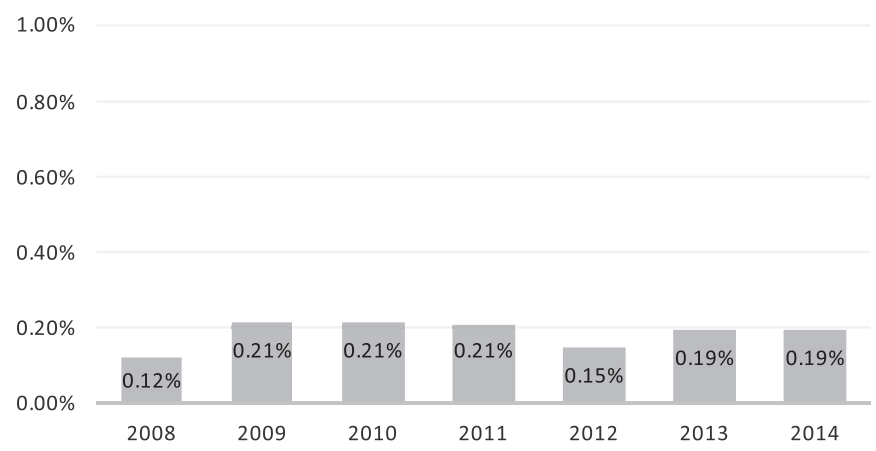

Fig 2. Average age of injured patients undergoing surgical intervention by year. Graphical representation of average age of surgical intervention represented by condition evaluated and year of evaluation. (ACL, anterior cruciate ligament; KCL, knee collateral ligament.)

trend in treating pediatric injuries surgically. The data presented herein can thus aid the patient-surgeon decisions tree towards a favorable outcome and relationship.

\section{Limitations}

A limitation to our study is that our data do not evaluate mechanism of injury and, thus, cannot delineate which injuries are due to sport versus other mechanisms such as trauma. Thus, we cannot be certain that these are all sports-related injuries. There is also inherent variability in who enters coding data and the accuracy of that data depending on provider and institution. In addition, 7 years may not be a sufficiently long study period to capture significant changes seen in the incidence of surgical management of adolescent sports injuries. In addition, the MarketScan database does not include public insurers, which could introduce bias as well. Duplicate ICD-9 injury entries were removed in this study. Although this duplicate entry may represent an additional injury, due to the nature of ICD-9 coding, this far more likely represents the previous injury sustained and follow up and as such was removed. This is required as our database and ICD-9 coding in general is not granular enough to tease out follow-up from reinjury. 
Table 4. Adjusted OR for Predisposing Factors Evaluated for Likelihood for Surgical Intervention by Diagnosis

\begin{tabular}{lccclcrrrr}
\hline Diagnosis/injury & Age, $y$ & OR & $P$ Value & Sex & OR & $P$ Value & Location & OR & $P$ Value \\
\hline ACL & $15-19$ & 5.39 & $<.0001$ & Male & 1.11 & $<.0001$ & Rural & 1.16 & $<.0001$ \\
KCL & $15-19$ & 1.57 & $<.0001$ & Female & 1.68 & $<.0001$ & Rural & 1.11 & .0197 \\
Meniscal & $15-19$ & 1.79 & $<.0001$ & Male & 1.27 & $<.0001$ & Rural & 1.11 & $<.0001$ \\
UCL & $15-19$ & 1.36 & $<.0001$ & Male & 1.14 & $<.0005$ & Rural & 1.08 & .0808 \\
O-S & $15-19$ & 13.98 & $<.0001$ & Female & 1.81 & $<.0001$ & Rural & 1.23 & .2472 \\
\hline
\end{tabular}

NOTE. A factor listed in age, sex, and location column is factor that is more likely to have been treated operatively. A $P$ value of $<.0001$ is considered statistically significant upon analysis for large data queries.

ACL, anterior cruciate ligament; KCL, knee collateral ligament; OR, odds ratio; O-S, Osgood-Schlatter; UCL, ulnar collateral ligament.

\section{Conclusions}

We found that surgical treatment of 5 common sports injuries remains stable with only KCL injuries and meniscal injuries showing an increase in surgical incidence. Average age of surgical intervention did not change significantly over the 7-year time span for any diagnosis.

\section{References}

1. National Federation of State High School Associations. 20162017 High School Athletics Participation Survey. 2017, https://www.nfhs.org/ParticipationStatistics/PDF/2017$18 \% 20$ High $\% 20$ School $\% 20$ Athletics $\% 20$ Participation $\%$ 20Survey.pdf. Accessed August 17, 2019.

2. Brenner JS, Council on Sports Medicine and Fitness. Sports specialization and intensive training in young athletes. Pediatrics 2016;138:e20162148.

3. DiFiori JP, Benjamin HJ, Brenner JS, et al. Overuse injuries and burnout in youth sports: a position statement from the American Medical Society for Sports Medicine. Br J Sports Med 2014;48:287-288.

4. Jayanthi N, Pinkham C, Dugas L, Patrick B, LaBella C. Sports specialization in young athletes. Sports Health 2012;5:251-257.

5. Lykissas MG, Eismann EA, Parikh SN. Trends in pediatric sports-related and recreation-related injuries in the United States in the last decade. J Pediatr Orthop 2013;33:803-810.

6. Bayt DR, Bell TM. Trends in paediatric sports-related injuries presenting to US emergency departments, 2001-2013. Injury Prev 2016;22:361.

7. Stracciolini A, Casciano R, Levey Friedman H, Meehan WP, Micheli LJ. Pediatric sports injuries. Am J Sports Med 2013;41:1922-1929.

8. Stracciolini A, Casciano R, Levey Friedman H, Stein CJ, Meehan WP, Micheli LJ. Pediatric sports injuries. Am J Sports Med 2014;42:965-972.

9. Beck NA, Lawrence JTR, Nordin JD, DeFor TA, Tompkins M. ACL tears in school-aged children and adolescents over 20 years. Pediatrics 2017;139:e20161877.
10. Petty DH, James RA, Glenn SF, Cain EL. Ulnar collateral ligament reconstruction in high school baseball players: Clinical results and injury risk factors. Am J Sports Med 2004;32:1158-1164.

11. Dodwell ER, Lamont LE, Green DW, Pan TJ, Marx RG, Lyman S. 20 Years of pediatric anterior cruciate ligament reconstruction in New York State. Am J Sports Med 2014;42:675-680.

12. Lawson BR, Comstock RD, Smith GA. Baseball-related injuries to children treated in hospital emergency departments in the United States, 1994-2006. Pediatrics 2009;123:e1028.

13. Leininger RE, Knox CL, Comstock RD. Epidemiology of 1.6 million pediatric soccer-related injuries presenting to US emergency departments from 1990 to 2003. Am J Sports Med 2007;35:288-293.

14. Lyman S, Koulouvaris P, Sherman S, Do H, Mandl LA, Marx RG. Epidemiology of anterior cruciate ligament reconstruction: Trends, readmissions, and subsequent knee surgery. J Bone Joint Surg Am 2009;91:2321-2328.

15. Werner BC, Yang S, Looney AM, Gwathmey FW Jr. Trends in pediatric and adolescent anterior cruciate ligament injury and reconstruction. J Pediatr Orthop 2016;36: 447-452.

16. Singh S, Smith GA, Fields SK, McKenzie LB. Gymnasticsrelated injuries to children treated in emergency departments in the United States, 1990-2005. Pediatrics 2008;121:e954.

17. Pollard KA, Shields BJ, Smith GA. Pediatric volleyballrelated injuries treated in US emergency departments, 1990-2009. Clin Pediatr (Phila) 2011;50:844-852.

18. Hodgins JL, Vitale M, Arons RR, Ahmad CS. Epidemiology of medial ulnar collateral ligament reconstruction: A 10-year study in New York State. Am J Sports Med 2016;44:729-734.

19. Mall NA, Chalmers PN, Moric M, et al. Incidence and trends of anterior cruciate ligament reconstruction in the United States. Am J Sports Med 2014;42: 2363-2370. 